\title{
Thermosets synthesized by metathesis: Multiscale lifetime approach
}

Cite as: AIP Conference Proceedings 2196, 020034 (2019); https://doi.org/10.1063/1.5140307 Published Online: 12 December 2019

Emmanuel Richaud, Jing Huang, and Pierre Yves Le Gac

ARTICLES YOU MAY BE INTERESTED IN

Synthesis and characterization of low- and high-molecular-weight products based on 5vinyl-2-norbornene AIP Conference Proceedings 2196, 020025 (2019); https://doi.org/10.1063/1.5140298

Dynamic and static behaviors of multilayered magneto-electro-elastic laminates with viscoelastic interfaces based on Winkler-Pasternak foundation

AIP Conference Proceedings 2196, 020030 (2019); https://doi.org/10.1063/1.5140303

Bis-amino functionalized iron $\mathrm{N}$-heterocyclic carbene as epoxy resins hardener and flame behaviour modifier

AIP Conference Proceedings 2196, 020035 (2019); https://doi.org/10.1063/1.5140308

\section{Lock-in Amplifiers up to $600 \mathrm{MHz}$

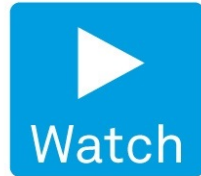

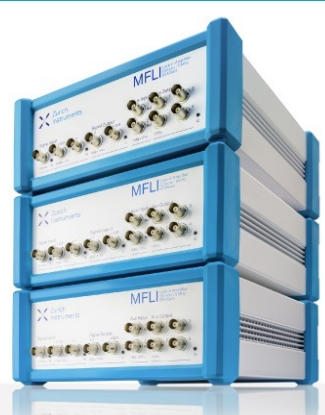




\title{
Thermosets Synthesized by Metathesis: Multiscale Lifetime Approach
}

\author{
Emmanuel Richaud $^{1 \mathrm{a}}$, Jing Huang ${ }^{1}$ and Pierre Yves Le $\mathrm{Gac}^{2}$ \\ ${ }^{1}$ Laboratoire PIMM, Arts et Métiers, CNRS, Cnam, 151 boulevard de l'Hôpital, F-75013 Paris, France \\ ${ }^{2}$ IFREMER, Service Matériaux et Structures, Centre de Brest BP70, F-29280 Plouzané, France \\ ${ }^{a}$ Corresponding author: emmanuel.richaud@ensam.eu
}

\begin{abstract}
This paper addresses the lifetime prediction of polydicyclopentadiene submitted to thermal oxidation, using a multiscale approach. The chemical changes monitored by FTIR revealed the depletion in double bonds and the appearance of carbonyls. Such molecular changes result in the drop of mechanical properties. A kinetic model was implemented to predict the degradation rate depending on external conditions (temperature, oxygen concentration). This model can be completed to take into account the effect of antioxidants (delaying the thermal degradation) and the oxygen diffusion effects (heterogenous degradation) so as to get closer of real cases.
\end{abstract}

\section{POLYDICYCLOPENTADIENE: ADVANTAGES, USES AND CHALLENGES}

Polydicyclopentadiene belongs to a family of thermosets obtained by Ring Opening Metathesis of Polyolefins catalyzed for example by ruthenium compounds catalyzing the opening of double bonds. Starting from the mixtures of poorly viscous solutions (monomer + catalyst) and (monomer + activator), a thermoset can be obtained in relatively short reaction times (less than $5 \mathrm{~min}$ ) without external heating which represents a huge interest for designing bulky polymers or composites parts. Those advantages are possibly counterbalanced by the presence of double bonds, and the use of organometallic compounds in high quantity (some $1000 \mathrm{ppm}$ ), both being known to favor the thermal degradation. The thermal stability of PDCPD remain thus an open question.

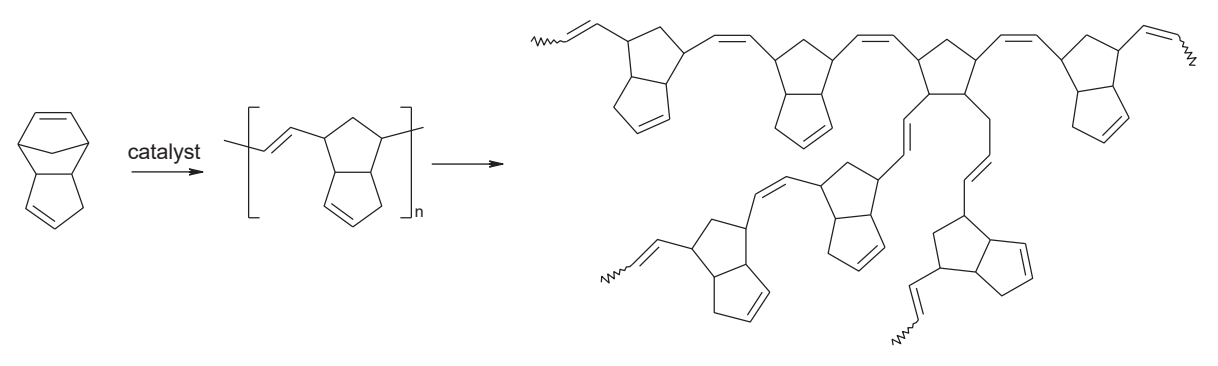

FIGURE 1. Polymerization of polydicyclopentadiene.

\section{MECHANICAL PROPERTIES CHANGES IN THERMALLY AGED PDCPD}

During its thermal ageing, PDCPD is shown to display a certain embrittlement as depicted in Figure 2. One can in particular observe a decrease in the elongation at break together with a slight increase in yield stress. Let us recall that in thermosets, both yield stress and toughness depend on the crosslink density [1]. In other words, both results point out the existence of a severe crosslinking process participating to the depletion of mechanical properties. 


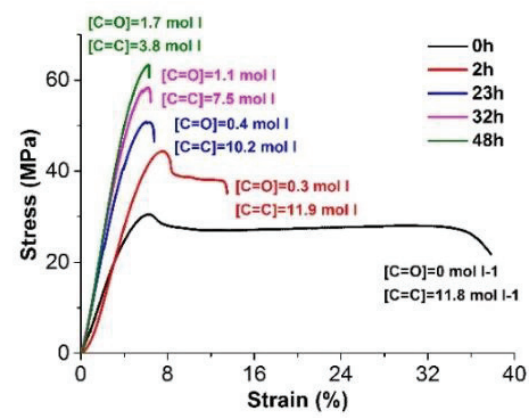

FIGURE 2. Tensile curves for PDPCD samples with varying exposure times at $80^{\circ} \mathrm{C}$ under air.

\section{STRUCTURAL CHANGES IN THERMALLY AGED PDCPD}

To confirm the previous results, thin $(<10 \mu \mathrm{m})$ film of PDCPD previously extracted from their processing antioxidants were aged in several conditions (temperature, oxygen pressure). Figure 3 displays typical results i.e. the increase of a broad band centered at $1710 \mathrm{~cm}^{-1}$ (ketones, carboxylic acids...) and the depletion of various absorption bands ascribed to double bonds at 720 and $970 \mathrm{~cm}^{-1}$.
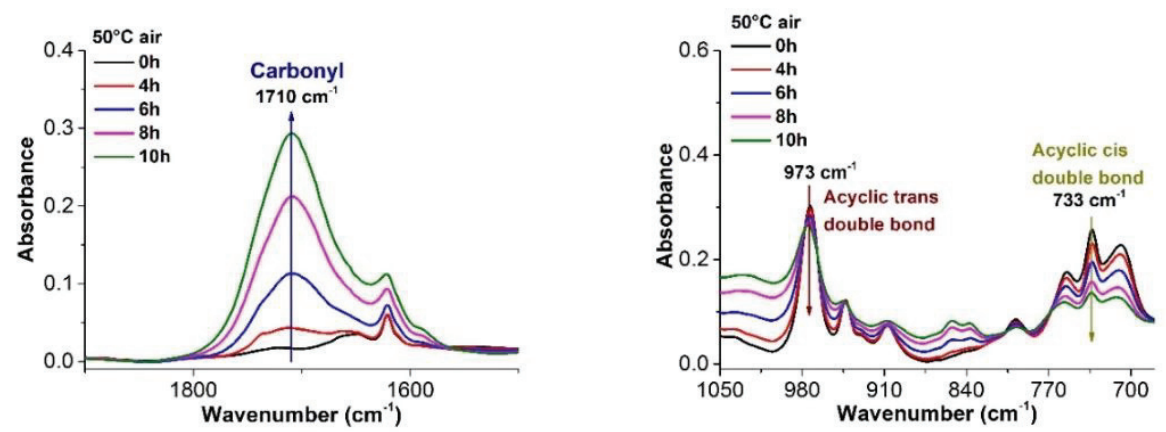

FIGURE 3. Changes in the FTIR spectra of PDCPD exposed at $50{ }^{\circ} \mathrm{C}$ in air.

The «autopsy » of degraded samples (from a mechanical point of view) suggested that lifetime was reached when carbonyl concentration (estimated from Beer Lambert law using $3001 \mathrm{~mol}^{-1} \mathrm{~cm}^{-1}$ as molar absorptivity for carbonyls) was close to $0.2 \mathrm{~mol} \mathrm{l}^{-1}$. Some oversimplified mechanisms are plotted in Figure 4:

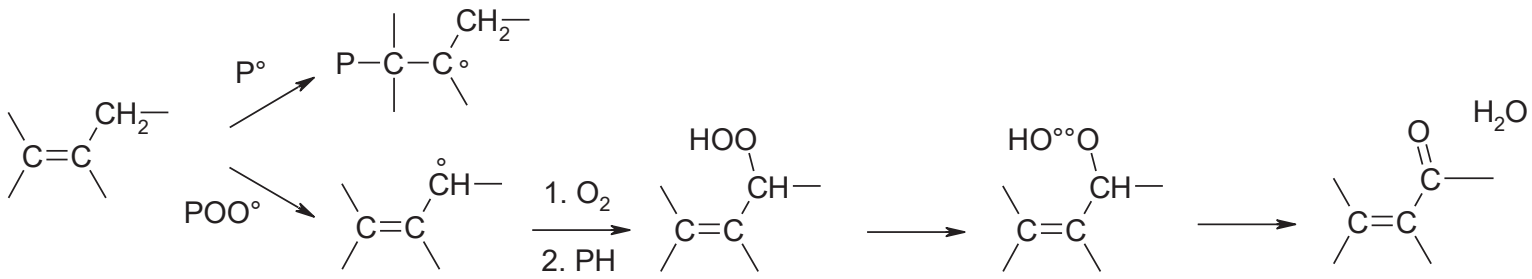

FIGURE 4. Simplified oxidation mechanism.

It seemed to us interesting to describe and model the rate of those changes using a classical kinetic scheme for the oxidation of hydrocarbon polymers (representing the complete mechanisms simplified in Fig. 4) and completed to take into account the presence of double bonds [2]:

(1u) $\mathrm{POOH} \rightarrow 2 \mathrm{P}^{\circ}+\gamma_{1}$ carbonyl

(1b) $\mathrm{POOH}+\mathrm{POOH} \rightarrow \mathrm{P}^{\circ}+\mathrm{POO}^{\circ}+\gamma_{1}$ carbonyl

$\mathrm{k}_{1 \mathrm{u}}$

(2) $\mathrm{P}^{\circ}+\mathrm{O}_{2} \rightarrow \mathrm{POO}^{\circ}$

$\mathrm{k}_{1 \mathrm{~b}}$

(3) $\mathrm{POO}^{\circ}+\mathrm{PH} \rightarrow \mathrm{POOH}+\mathrm{P}^{\circ}$

$\mathrm{k}_{2}$

$(\mathrm{A}-1) \mathrm{P}^{\circ}+$ double bond $\rightarrow$ crosslinking $+\mathrm{P}^{\circ}$

$\mathrm{k}_{3}$

(A-2) $\mathrm{POO}^{\circ}+$ double bond $\rightarrow \gamma_{1}$ carbonyl $+\mathrm{P}^{\circ}$

$\mathrm{k}_{\mathrm{a} 1}$

(4) $\mathrm{P}^{\circ}+\mathrm{P}^{\circ} \rightarrow$ double bond $+\mathrm{PH}$

$\mathrm{k}_{\mathrm{a} 2}$

(5) $\mathrm{P}^{\circ}+\mathrm{POO}^{\circ} \rightarrow \mathrm{POOH}+$ double bond

$\mathrm{k}_{4}$

(6) $\mathrm{POO}^{\circ}+\mathrm{POO}^{\circ} \rightarrow$ carbonyl $+\mathrm{POH}$

$\mathrm{k}_{5}$

$\mathrm{k}_{6}$ 
where $\mathrm{P}^{\circ}, \mathrm{POO}^{\circ}, \mathrm{POOH}, \mathrm{PH}$ are respectively alkyl, peroxy, hydroperoxides and reactive site concentration, $\mathrm{k}_{\mathrm{i}}$ are kinetic rate constants (depending only of temperature according to Arrhenius law) and $\gamma_{1}$ is the yield in carbonyls from $\mathrm{PO}^{\circ}$ decomposition. This scheme leads to a differential system, giving the outputs of the model as for example the concentration in carbonyls and double bonds:

$$
\begin{gathered}
\frac{d[\mathrm{P}=\mathrm{O}]}{d t}=\gamma_{1} k_{1 u}[\mathrm{POOH}]+\gamma_{1} k_{1 b}[\mathrm{POOH}]^{2}+k_{6}\left[\mathrm{POO}^{\circ}\right]^{2}+\gamma_{1} k_{a 2}\left[\mathrm{POO}^{\circ}\right][\mathrm{F}] \\
-\frac{d[C=C]}{d t}=-k_{a 1}\left[P^{\circ}\right][\mathrm{C}=\mathrm{C}]-k_{a 2}\left[\mathrm{POO}^{\circ}\right][\mathrm{C}=\mathrm{C}]+k_{4}\left[\mathrm{P}^{\circ}\right]^{2}
\end{gathered}
$$

Let us stress that, even if only some of the reactions of mechanism generate carbonyls or consume double bonds, the whole set of rate constants must be known to calculate $[\mathrm{POOH}],\left[\mathrm{POO}^{\circ}\right] \ldots$ and predict the chemical changes in the polymer. Using the detailed methodology for estimating those later published elsewhere [3], we obtained a kinetic model able to simulate the oxidation of unstabilized PDCPD in a wide range of temperatures as shown in Figure 5. This latter must now be completed to get closer of practical cases and predict the time at which the « critical » carbonyl limit $\left(0.2 \mathrm{~mol} \mathrm{l}^{-1}\right)$ is reached in practical conditions.
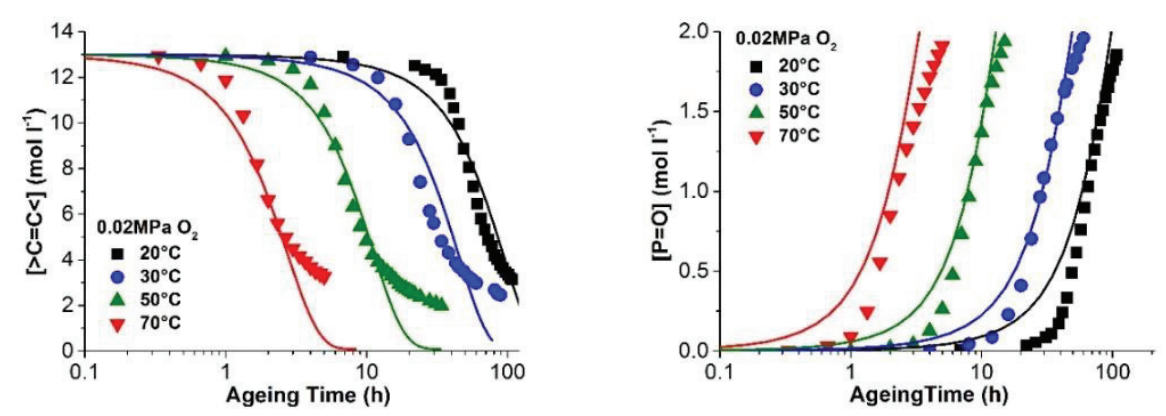

FIGURE 5. Changes of carbonyl and double bonds concentration for various conditions and simulations by kinetic modeling (full lines).

\section{EFFECT OF ANTIOXIDANTS}

Antioxidants are currently added to hydrocarbon polymers to slow down oxidation kinetics. Among them, Tinuvin 123 (Figure 6) is a promising candidate since it does not interact with catalyst during the network polymerization, and it displays an elevated solubility limit (more than $1500 \mathrm{ppm}$ ) thus limiting the possible demixion effects lowering its efficiency. Figure 7 illustrates the stabilizing effect of the antioxidant.

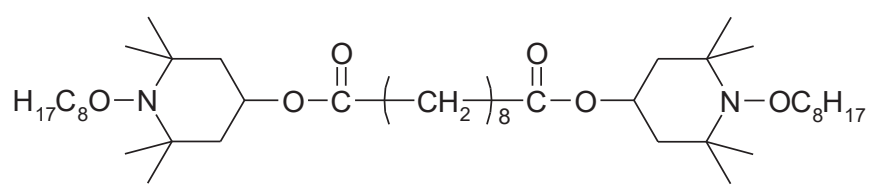

FIGURE 6. Structure of Tinuvin 123.

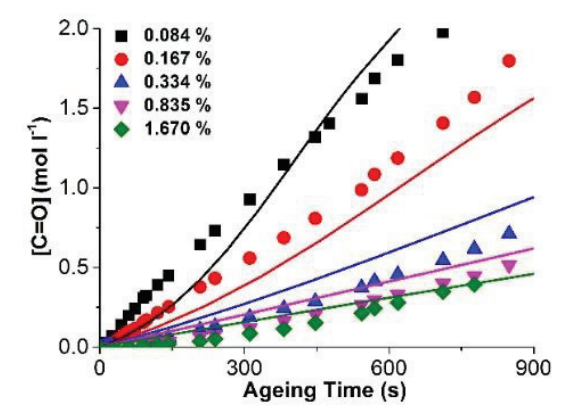

FIGURE 7. Kinetic curves for carbonyl build up at $50^{\circ} \mathrm{C}$ of PDCPD with varying ratio of Tinuvin 123 and kinetic modelling (full line).

The kinetic model was thus completed by adding two reactions describing the action of Tinuvin 123: 


$$
\begin{array}{ll}
>\mathrm{NOP}+\mathrm{POO}^{\circ} \rightarrow>\mathrm{NO}^{\circ}+\text { inactive product } & \mathrm{k}_{\mathrm{NOP}} \\
>\mathrm{NO}^{\circ}+\mathrm{P}^{\circ} \rightarrow>\mathrm{NOP} & \mathrm{k}_{\mathrm{NO}}
\end{array}
$$

$\mathrm{k}_{\mathrm{NO}}$ being estimated from the classical literature (for example for nitroxide controlled polymerization) [4], $\mathrm{k}_{\mathrm{NOP}}$ was estimated from best curve fitting so that we dispose now of a model valid for PDCPD stabilized with various kinds of alkoxylated hindered amine stabilizers and later all the hindered amine family.

\section{EFFECT OF SAMPLE THICKNESS AND DIFFUSION LIMITED OXIDATION}

The existence of an oxidation gradient in bulky polymers [5,6] is illustrated by microscopic observations of PDCPD (Figure 8) showing a dark edge corresponding to oxidized layer.
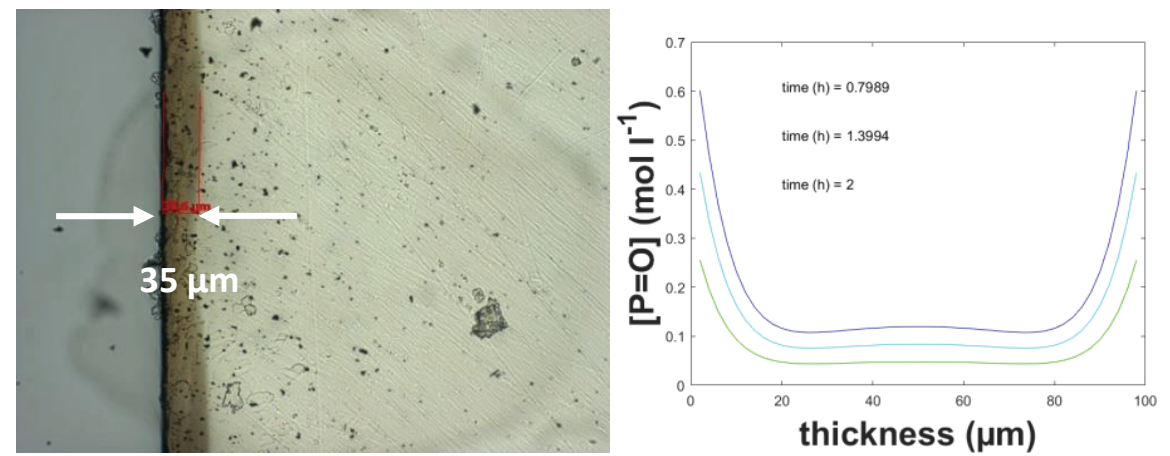

FIGURE 8. Optical measurement of degraded layer (left) and simulation by the model (right).

The thickness of oxidized layer can be expressed as the result of a competition between oxidation rate in the surface and oxygen diffusivity as shown by the balance equation for oxygen consumption:

$$
\frac{\partial\left[O_{2}\right]}{\partial t}=D_{O 2} \frac{\partial^{2}\left[O_{2}\right]}{\partial x^{2}}-k_{2}\left[P^{\circ}\right]\left[O_{2}\right]+k_{6}\left[P O O^{\circ}\right]^{2}
$$

In other words, using oxygen diffusion and solubility parameters measured typically by permeametry [7], the model can be completed to predict the thickness of degraded layers for « in use » ageing conditions.

\section{CONCLUSIONS}

A model for non-empirical lifetime prediction is illustrated in the case of polydicyclopendadiene undergoing thermal oxidation. Basing on temperature (for calculating rate constants), concentration in antioxidant, sample thickness, its main outputs (carbonyl and double bonds concentration) can be linked to polymer mechanical properties. Such a model can hence predict lifetime for a wide range of practical cases.

\section{ACKNOWLEDGMENTS}

Agence Nationale de la Recherche is gratefully acknowledged for having funded this study (Project VRPOM - Vieillissement des Réseaux Polymérisés par Métathèse - 2016-2019).

\section{REFERENCES}

1. J.P. Pascault, H. Sautereau, J. Verdu, R.J. Williams, Thermosetting polymers, Marcel Dekker New York, 2002.

2. X. Colin, L. Audouin and J. Verdu, Polym. Degrad. Stab. 92, 886-897 (2007).

3. J. Huang, A. David, P.-Y. Le Gac, et al., Polym. Degrad. Stab. 166, 258-271 (2019).

4. J. Nicolas, Y. Guillaneuf, C. Lefay, et al, Prog. Polym. Sci. 38, 63-235 (2013).

5. A. Quintana and M.C. Celina. Polym. Degrad. Stab. 149, 173-191 (2018).

6. Y. Hu, Y. Zhang, and S. Nutt, Polym. Comp. 39,1742-1751, (2018).

7. V. Defauchy, P.Y. Le Gac, A. Guinault, Polym. Degrad. Stab. 142, 169-177 (2017). 